\title{
Design and Application of Distance Education Platform for the New Professional Peasant
}

\author{
http://dx.doi.org/10.3991/ijet.v10i4.4704 \\ Yujia Ren ${ }^{1}$, Menglong $\mathrm{Li}^{2}$, Yixiong $\mathrm{Wu}^{3 *}$ \\ ${ }^{1}$ Xiangtan Vocational Technical College, Xiangtan, China \\ ${ }^{2}$ University of Science and Technology, Xiangtan, China \\ ${ }^{3}$ Hunan Radio and TV University, Changsha, China
}

\begin{abstract}
As distance learning systems become significant teaching means, this technology is becoming mature and penetrating teaching practices. This study researched the design and application of a tablet computer control system in a distance education platform for new professional peasants. The system described in this paper consisted of a computer client, a tablet computer, a projector and a wireless access point. The computer client is the center component. The tablet computer is connected to the computer client via a wireless access point. The projector is connected to the computer client. The tablet computer sends an operation to the computer client in the form of a message. Analysis execution is conducted by the computer client to operate courseware content located at the computer client via the tablet computer. This synchronously displays the courseware content. Transmission of the courseware content through a screenshot has a wide range of applications and strong universality.
\end{abstract}

Index Terms-new professional peasants, distance education, control system, application

\section{INTRODUCTION}

Since the reform and opening up, the urbanization in China has been improved rapidly. In 2013, the urban population increased to 730 million, with an urbanization rate of $53.7 \%$ and China has become one of the countries with the rapidest urbanization speed in the world [1]. With the acceleration of urbanization and transfer of a lot of young labor forces in the rural areas, the practical talents in the rural areas have flowed out greatly. The serious aging and weakening of rural labor forces have caused a series of problems, like the degeneration of activity in the rural society and reduction of agricultural labor force [2]. Therefore, it has been urgent to strengthen the development of human resources in the rural areas and cultivate the new professional farmers [3]. The new professional farmers mean the agricultural practitioners living in rural areas or towns who take agricultural production, operation or service as the main occupation and agricultural income as the main living source with scientific and cultural quality, mastering the modern agricultural production skills and having certain operation and management ability [4]. Training new professional peasants is an important approach to improving their quality of life and increasing their income. Because traditional training for professional peasants has problems (such as short training time and a dingle training mode), it cannot satisfy the demands of modern professional peasants for knowledge and technology [5]. Implementation of distance education in rural areas and the design of network training courses that can promote peasants' effective study and online interaction can free new professional peasants from time and place limitations and give full play to their initiative [6].

Tablet computers are a very important platform and tool for digital reading. Colleges, middle schools, primary schools and cultural institutions provide lectures, videos, e-books and other resources as well as open classes. Many websites also launch tablet computer applications for open classes and attract a large number of distance learners [7]. The research report of American online video techniques and the service provider Ooyala in the third quarter of 2011 shows video viewing time by tablet computer users is $28 \%$ longer than desktop computer or laptop users, and the tablet user is twice as likely to completely view the video [8].

The application of tablet computer undoubtedly brings new opportunities for discussing and studying distance education. How to explore more convenient and popular distance education modes for universal education and lifelong learning that address needs/interests of the students is a topic that needs to be solved.

Due to the popularity and influence of the Apple Company, Apple tablet computers occupy a large market share in the tablet computer market. But Apple tablet computers apply the special operating system IOS from the Apple Company. Such a mobile operating system is greatly restricted in compatibility [9]. Since Microsoft Office is very popular, teachers often use Microsoft Office and other editing tools to prepare courseware. When PPT and documents made with Word are displayed via a tablet computer, the display effect has great differences. This depends on software compatibility, which is very hard to solve in the short term. For Microsoft Office documents with complex formats, versions may differ in file parsing and rendering. This results in differences when clients display the content on a tablet computer or leads to differences expected by the teacher regarding the document. This will affect teaching.

Aiming at the problems with the existing technology, this study deigned a method and system to control courseware synchronization for tablet computers. The tablet computer sends instructions containing courseware to the computer client to achieve the purpose of opening the courseware, operating the courseware, and commenting on the courseware. 


\section{DISTANCE EDUCATION PLATFORM BASED ON MOODLE PLATFORM}

Moodle platform function [10] mainly includes three parts: user management, course management, and teaching activity.

\section{A. User management}

The user management function in a Moodle platform mainly involves user account management and user rights allocation. The account management function mainly includes browsing and editing user information, adding management fields, manually adding user accounts or adding multiple users at one time through uploading files, batch processing of users, uploading users' head portraits, creating groups, deleting users, etc. [11]. User rights management mainly includes setting user strategies, adding and deleting website administrators, defining users, editing users' rights, allocating system roles, checking system rights, etc. User strategy setting can complete setting the default role for visitors and users and the course creator's role, and it can also set display information while searching for users. The "system role" allocated by Moodle belongs to the total station role, including the homepage of the station and all courses on the platform.

Moodle also provides the function of checking rights to the system, i.e. selects specific users and checks their rights in the system. If students do not participate in the activities for a long time, administrators may delete them from the course, and teachers may set a log-in password for the course to prevent illegal users from disturbing the teaching activities and to ensure the safety of the teaching resources and student information.

\section{B. Course management}

Moodle integrates website functions. Users may no longer establish websites alone, but they can directly create education and training websites as well as various courses via Moodle [12]. The Moodle platform offers front-stage display and back-stage management. Teachers may edit any content in Moodle at any time. Online compilers with complete function are embedded in the Moodle so users can conveniently change the webpage and upload all kinds of learning resources. Teachers may design courses through adding resources and activities and add course materials, including learning videos, electronic drafts and electronic display documents. Learners may select learning resources they like.

\section{Teaching activity}

While implementing teaching activities, the Moodle platform can record learners' various operations, and teachers can check the learning report for any student, including course access, both time and place. Teachers can also check students' participation in a teaching module [13]. Teachers can identify students' demands and learning situations through voting and questionnaire surveys.

It is necessary to continuously improve and perfect course and platform construction. Through the Moodle platform, teachers can organize students to carry out various types of learning, such as inquiry-based learning, group cooperation studies, and independent studies. In the learning process, learners can naturally complete self- construction of knowledge and boost their enthusiasm through interactions with other students or teachers.

\section{DESIGN OF DISTANCE EDUCATION PLATFORM FOR NEW PROFESSIONAL PEASANTS}

\section{A. Design of system teaching mode}

How to achieve remote access to an education platform via a tablet computer is a key point in this paper. This system was designed by using the structural system of Moodle. In Moodle-based distance training for peasants, the peasants were the training subjects. They could as learners gain teaching materials or as course teachers share their experience with other learners. This project combined the unique advantages of a Moodle platform and referred to a Moodle-based distance training mode to propose Moodle-based distance training mode for the peasants.

The modularization of Moodle is oriented to a dynamic learning environment. Its powerful course management function is mainly composed of assignment, voting, examination, and questionnaire survey modules. Each module fully reflects features and advantages of online education suitable for online learning, group cooperation learning, and independent study. Students first log into the platform, register with the mailbox confirmation mode, and save their username and password. After logging in, students may choose training courses according to their needs and preferences. In the learning process, chat rooms and discussion zones may be utilized to exchange experiences with other students, discuss problems, and interact with training experts through the chat room. Training is conducted on the basis of rich resources and diversified activities. Resources should contain documents: course videos, linked external websites, and experience reports by other students. The activities include voting, questionnaire surveys, video conferences and live videos, etc. that can meet the peasants' learning demands.

\section{B. System function design}

A mobile learning system based on a tablet computer includes the client and server $(\mathrm{C} / \mathrm{S})$. The system operates on an IOS system. Since mobile learning has diversified the requirements for the environment, learning resources should support online and offline updating of wireless WIFE or a $3 \mathrm{G}$ network. In view of the data flow of online updates, users must be able to conveniently search the information they need. The online communication data flow is small, and the response speed is fast. The client system is configured in the tablet computer. Communication with the server adopts a Socket HTTP protocol. The communication data are encapsulated. Finally, the text and video learning resources are stored in a database for the convenience of system database maintenance. The functional structure of the client is shown in Figure 1.

The client of the mobile learning system is support guarantee as an iPad client. The optimized $\mathrm{C} / \mathrm{S}$ system structure Web service accepts client requests, visits the database to gain corresponding resources and information, and returns the processing results to the client. The server management system is responsible for managing the system users, students' information, course resources, forum, and learning schedule management, etc. The server function module is shown in Figure 2. 


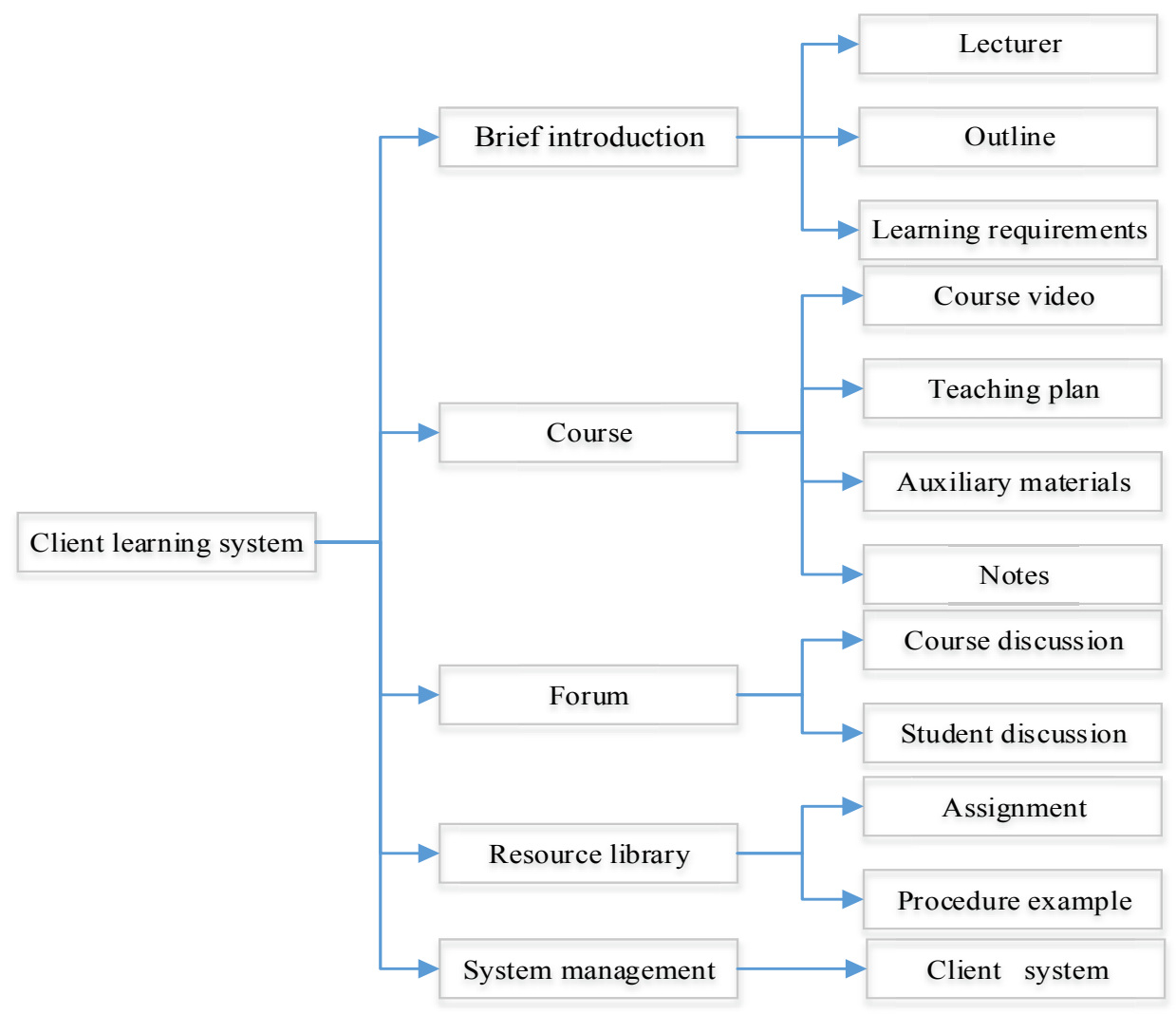

Figure 1. Functional diagram of client learning system

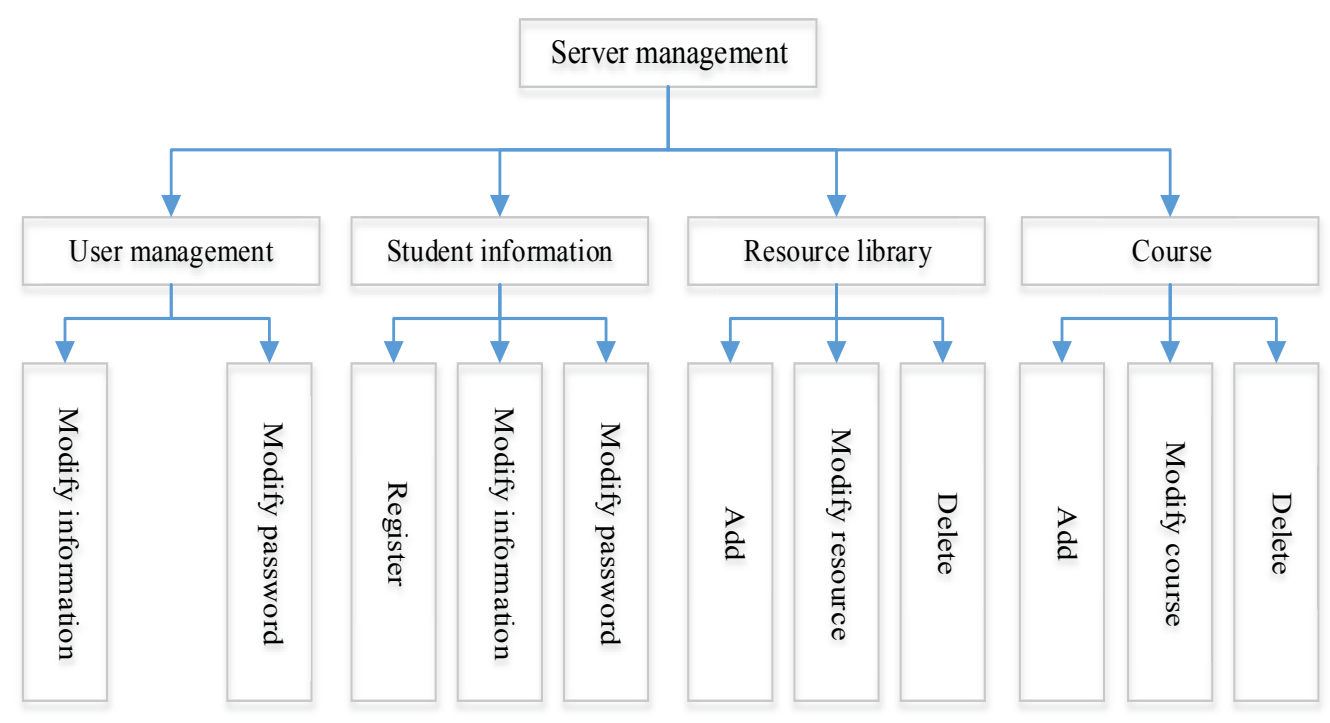

Figure 2. Structure diagram of server function module

\section{Multimode-BASED ONLINE TEACHING EXPERIMENT}

System function includes the synchronization method of opening and operating the tablet computer as well as approving the courseware. System-related components include the computer client, tablet computer, projector and wireless access point. The computer client is the center component. The tablet computer is connected to the computer client via a wireless access point. The projector is connected to the computer client. The tablet computer sends a message to the computer client. Analy- sis execution is conducted by the computer client to operate courseware content for the computer client via the tablet computer. The projector is used to display the courseware content at the computer client, and the wireless access point is used for information transmission between the computer client and the tablet computer.

The tablet computer control system consists of a synchronous processing subsystem of the computer client and a synchronous processing subsystem of the tablet 


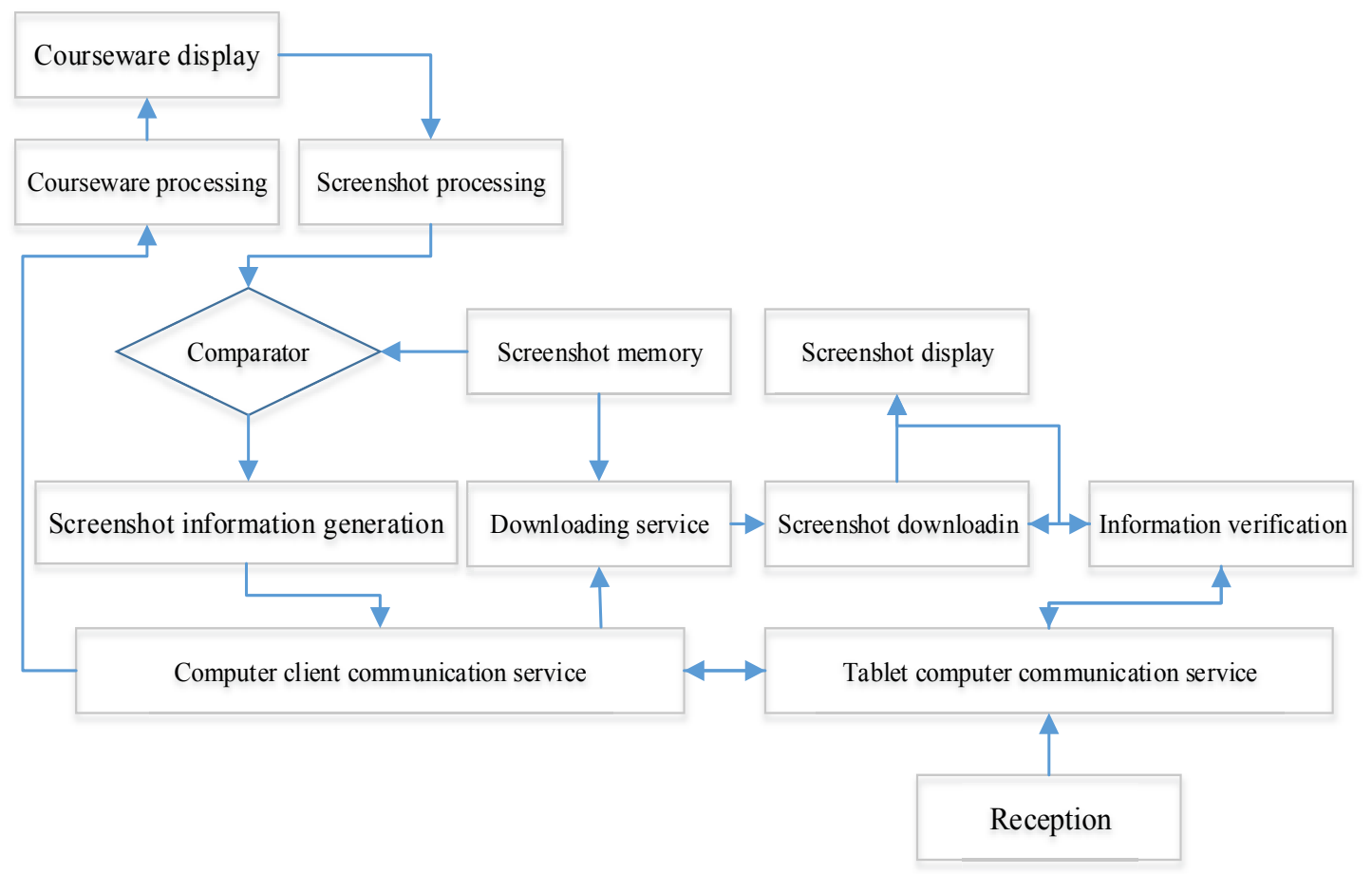

Figure 3. Flow chart of teaching operation

computer. The computer client is used to manage various kinds of courseware, transform courseware content to icon format, and transmit the content to the tablet computer client via a wireless network. The tablet computer client receives the pictures transmitted by the computer client and sends operation instructions to the computer client. The system flow is shown in Figure 3.

\section{A. Open courseware}

The specific steps of the synchronization method to open the courseware are as follows:

1. Establish connection between the tablet computer and the computer client.

2. The tablet computer sends the instruction of "opening the courseware" to the computer client.

3 . The computer client processes according to the message sent by the tablet computer.

4. The tablet computer processes screenshot information received.

Before the tablet computer starts the courseware, it first establishes a UDP connection with the computer client. After the UDP connection is established, the computer client sends a network IP and port of where the computer client is to the tablet computer through a UDP connection to quickly and dynamically establish a TCP connection with the computer client. When the network signal is not stable, the tablet computer may not receive a UDP. At this moment, the tablet computer will automatically use the fixed IP address. This can ensure establishment of a TCP connection when a UDP cannot be received. After the two establish a TCP connection, they may communicate with each other and prepare for transmitting relevant instructions and pictures. The tablet computer sends a verification code to the computer client. After the com- puter client passes the verification, a corresponding pair relationship will be established.

Corresponding courseware can be selected on the tablet computer, and users can click to open the courseware. The tablet computer opens the courseware according to corresponding instructions, packages the courseware to the corresponding message and sends it to the computer client. Then the computer client processes the message and analyzes the corresponding message. Users can open corresponding courseware at the computer client and start the timer to shoot the screen of the courseware at the computer client. The first screenshot of the courseware is saved in the internal storage and confirmed as the picture to be sent. Then every screenshot is compared with the picture to be sent, which is saved in the internal storage. If they are same, the screenshot will not be sent. If they are different, the new screenshot is saved in internal storage and confirmed as the screenshot to be sent. After the screenshot to be sent is confirmed, this screenshot will be saved in a special space and form the screenshot information. Screenshot information includes courseware expression information, screenshot expression information, and the relative path of screenshot saving. The computer client packages screenshot information as a message and sends it to the tablet computer. The tablet computer processes the screenshot information received, reads the relative path of the screenshot saved in the screenshot information and assembles an http URL address to download the screenshot from the computer client. After completion of downloading, the screenshot is saved in a screenshot downloading and storage unit. The screenshot is displayed on the tablet computer. The interface effect of the tablet computer login-open courseware is shown in Figure 4. 

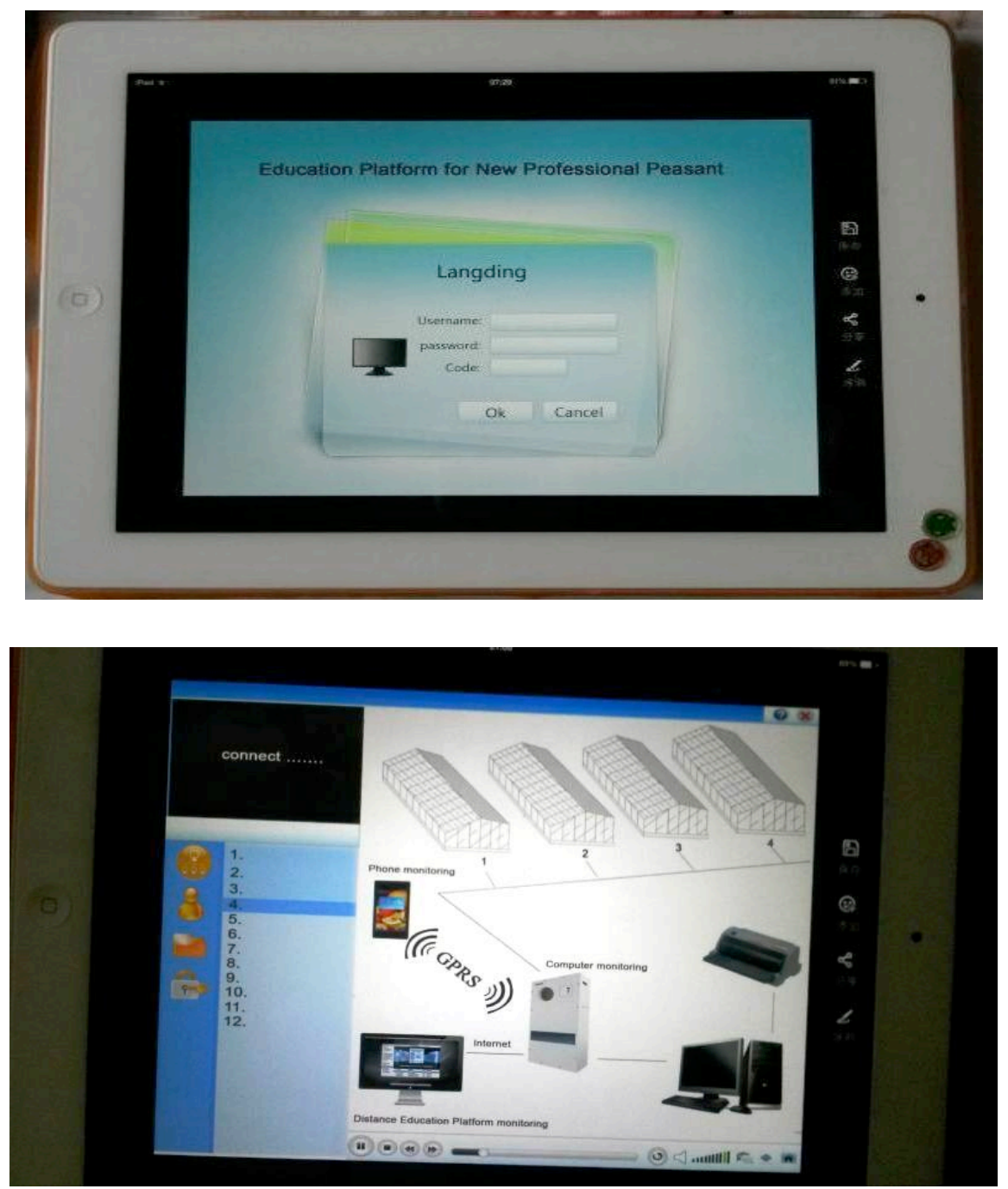

Figure 4. Interface effect of tablet computer login-open courseware

\section{B. Operate courseware}

The specific steps of the synchronization method to operate the courseware are as follows:

1. A connection is established between the tablet computer and computer client.

2. The tablet computer sends the instruction of "operating the courseware" to the computer client and operates the courseware opened. Then the tablet computer packages the corresponding operation instructions to the corresponding message and sends it to computer client.

3 . The computer client processes according to the message sent by tablet computer.

4. The tablet computer processes the screenshot information received.

\section{Comment courseware}

The specific steps of the synchronization method to comment on the courseware are as follows:

1. In the initialization phase, the transparent layer is set up at the top of the courseware content area displayed by the computer client. Courseware display content is at the bottom; the length and width of the screen display area of the computer client and tablet computer are acquired respectively to calculate the length ratio and width ratio of the two. The coordinates of the screen display area of the computer client and tablet computer are established. The peak at the top left serves as the origin of coordinates.

2. Comments on the courseware on the tablet computer

3. The coordinate value is transformed at the computer client.

4. Connects these points in order at the transparent layer at the computer client according to the data series relationship to form a comment track so as to comment on the courseware synchronously.

\section{Application of distance education platform for new professional peasants}

After the design is finished, case implementation will be conducted next. To verify the application effects of the tablet computer control system in distance education for new professional peasants, 120 peasants at a rural experimental site were selected at random as objects of study. Sixty peasants were chosen in the experimental group, while another 60 peasants were in the control group. 
PAPER

Design and Application of Distance EduCATion Platform for New Professional Peasant

TABLE I.

EVALUATION OF DISTANCE EDUCATION PLATFORM BY NEW PROFESSIONAL PEASANTS

\begin{tabular}{lcccc}
\hline \multicolumn{1}{c}{ Group } & Keen interest & Interested & General & No interested \\
\hline Control group (NO) & 25 & 15 & 20 & 10 \\
Experimental group (NO) & 35 & 18 & 6 & 1 \\
\hline
\end{tabular}

Peasants in the control group were taught according to a traditional teaching mode, while peasants in the experimental group applied distance teaching modes based on the tablet computer control system.

The peasants generally expressed that the tablet computer distance learning system could deepen understanding of concepts and content and could boost learning efficiency. In the teaching process, the peasants' initiative for learning was greatly motivated, and the effects of interactive learning between teachers and students were obvious. Most peasants preferred the novel, heuristic, and new teaching course. Such a classroom helped them improve their professional skills. However, in the actual implementation process, since some peasants lacked selfcontrol; they spent a lot of time on unrelated activities in the distance learning system. Although the teachers managed them, the learning effects were not obvious. This affected the experimental results to some extent. The peasants' evaluation results for distance education are shown in Table 1.

The results in the experimental group are better than the results in the control group. In the experimental group, the peasants' were motivated to learn. The investigation found that various teaching materials were saved in the network and could be recycled. This saved the time for blackboard writing, alleviated the teachers' work intensity, and boosted training efficiency. The peasants could $\log$ into the distance learning system anytime and anywhere and their deepen memory and understanding of the information. This also verifies it is feasible to apply a tablet computer control system in the platform and offers help for construction of such systems in new rural areas.

\section{CONCLUSIONS}

This project studied the application of a tablet computer control system in a distance education platform, designed and implemented the distance education platform for peasants and applied it in practice. The results in the experimental group were better than the results in the control group, which verifies the feasibility of the application of a tablet computer control system in a distance education platform.

The tablet computer has strong points. Its application in teaching activities stimulated the interest of many of the peasants and reached the expected effect. But it has a strong amusement factor. A small number of peasants ignored the distance learning system due to their interest in the tablet computer. This problem should be evaluated in follow-up research.

\section{REFERENCES}

[1] Xia Q.J., Simmons C., "Diversify and prosper: Peasant households participating in emerging markets in northeast rural China," China Economic Review, vol. 15, no. 4, pp. 375-397, April 2004. http://dx.doi.org/10.1016/j.chieco.2003.09.001

[2] Zhang L., Zhang Y., Zhao B.H., "Selection of Training Mode for New Professional Farmers in China," Higher Agricultural Education, vol. 17, no. 4, pp. 107-112, April 2013.
[3] Zhao D.Y., Hong L., "The Social Endowment Insurance of Professional Farmer from the Underdeveloped Areas," Journal of South China Agricultural University (Social Science Edition), vol. 5, no. 2, pp. 8-13, February 2006.

[4] Zhu Q.Z., "New professional Farmers and Family Farm," China Agricultural University Journal of Social Sciences Edition, vol. 30, no. 2, pp. 157-159, June 2013.

[5] He M.F., Li C., Tong T., Ma T.L., "A model of peasant labor in China," Physica A: Statistical Mechanics and its Applications, vol. 387, no. 7, pp. 1621-1627, March 2008.

[6] Maria H.Z., "The role of the peasant in China's development plans,' Communist and Post-Communist Studies, vol. 42, no. 1, pp. 103-114, March 2009. http://dx.doi.org/10.1016/j.postcom stud.2009.02.002

[7] Pedro P.T., Kathryn A.H., Alex M., "Use of Tablet (iPad®) as a Tool for Teaching Anesthesiology in an Orthopedic Rotation," Brazilian Journal of Anesthesiology, vol. 62, no. 2, pp. 214-222, March-April 2012. http://dx.doi.org/10.1016/S0034-7094(12) 70119-8

[8] Tyser A.R., Beckmann J., Weng C., O'Farrell A., Hung M., “A Randomized Trial of the Disabilities of the Arm, Shoulder, and Hand Administration: Tablet Computer Versus Paper and Pencil," The Journal of Hand Surgery, vol. 40, no. 3, pp. 554-559, March 2015. http://dx.doi.org/10.1016/j.jhsa.2014.10.046

[9] Steven H., Foster R.G., Richard S.C, Larry A.N., "Prospective pilot study of a tablet computer in an Emergency Department," International Journal of Medical Informatics, vol. 81, no. 5, pp. 314-319, May 2012. http://dx.doi.org/10.1016/j.ijmedinf. $\underline{2011.12 .007}$

[10] Teresa M.B., Ana S.F., "The role of new technologies in the learning process: Moodle as a teaching tool in Physics," Computers \& Education, vol. 52, no. 1, pp. 35-44, January 2009. http://dx.doi.org/10.1016/j.compedu.2008.06.005

[11] Tomas E.R., Pedro M.L., "The acceptance of Moodle technology by business administration students," Computers \& Education, vol. 58, no. 4, pp. 1085-1093, May 2012. http://dx.doi.org/10.1016/j.compedu.2011.11.012

[12] Isabel N.C., Laura V.C., María R.D., "E-learning and face to face mixed methodology: Evaluating effectiveness of e-learning and perceived satisfaction for a microeconomic course using the Moodle platform," Computers in Human Behavior, vol. 29, no. 2, pp. 410-415, March 2013. $\quad$ http://dx.doi.org/10.1016/ j.chb.2012.06.006

[13] Sun Y.X., Liu C., Cui X.G., "The design and implementation of library's user training system based on moodle," Journal of Digital Information Management, vol. 11, no. 4, pp. 298306, August 2013.

\section{AUTHORS}

Yujia Ren (First author) is a lecturer in Xiangtan Vocational Technical College, Xiangtan, 411005, China. Her research interests include distance learning and vocational education (renyujia@163.com)

YiXiong Wu (Corresponding author) is a professor in Hunan Radio and TV University, Changsha, 410004, China. His research interests include cultivation of professional peasant (wuyixiong100@126.com)

Menglong $\mathbf{L i}$ is an associate professor at Hunan University of Science and Technology, Physical Education Institute, Xiangtan, 411201, China. His research interests include distance education of peasants (lm10713@yeah.net)

This paper was supported by National Social Science Fund Project [BKA140034]. Submitted 07 May 2015. Published as resubmitted by the authors 20 August 2015. 